\title{
A QUERELA ENTRE HELVÉTIUS E DIDEROT: ENTENDIMENTOS DISTINTOS DESENVOLVIMENTO HUMANO E MORAL. ${ }^{1}$
}

\author{
Camila Sant'Ana Vieira Ferraz Milek \\ $(\mathrm{UFPR})^{2}$ \\ csvferraz@hotmail.com
}

Resumo: Existe uma reconhecida proximidade entre os materialistas franceses do século XVIII que teria se mostrado tanto em investigações sobre a natureza quanto à moral e organização pública. Porém, as divergências entre eles podem desencadear um entendimento muito diferente sobre como se considera uma sociedade. Por isso é necessário analisar no detalhe tais divergências para determinar seu ponto nevrálgico. $O$ presente artigo dedicase à investigação das críticas feitas por Diderot à Helvétius, reunidas em Réfutations d'Helvétius (DIDEROT,1783). Para tanto, centra-se na distinta concepção da natureza da sensibilidade humana e sua importância para o desenvolvimento humano no que concerne à educação e a moral.

Palavras-chave: Helvétius, Diderot, sensibilidade, educação.

O século XVIII foi um período de modificação na concepção do mundo em vários aspectos. Diante da revolução científica e do fortalecimento das ciências empíricas, foi preciso perguntar novamente: qual é a fonte do conheci-

\footnotetext{
${ }^{1}$ Recebido: 21-02-2018/ Aceito: 24-05-2018/ Publicado online: 12/04/2020.

${ }^{2}$ Camila Sant'Ana Vieira Ferraz Milek é Professor Adjunto da Universidade Federal do Paraná, Paraná, Brasil.
} 
mento? Quais são as possibilidades do ser humano? Que lugar ele ocupa entre os demais seres? Ao mesmo tempo, diante da impostura dos costumes e das descobertas sobre diferentes sociedades e indivíduos, perguntou-se: como funciona o desenvolvimento da moralidade, se há umapluralidade de costumes a serem levados em conta? Como reavaliar uma sociedade e trilhar um caminho seguro para sua melhora?Em uma época de transformação e reavaliação do pensamento estruturante nas ciências da natureza e também nas questões sociais, foi necessário que se encontrasse um solo seguro conforme a realidade que permitisse também a superação de problemas sociais. $O$ conceito de natureza foi intimado para essa tarefa, por causa das questões que pode resolver e como forma de reunir correntes de pensamento ali presentes e justificar práticas da sociedade que seriam mais condizentes com o que se entende por ser humano. Porém, mesmo que o conceito de natureza possa resolver muitas questões, ele suscita várias outras, já que a natureza é concebida de várias formas.

Sobre a multiplicidade de usos, menções e relações que o tema da natureza desperta no séc. XVIII, contamos com a obra de Jean Ehrard, L'idée de Natureen France à l'aubedesLumières (1970), que mostra como a natureza estava no centro das disputas em temas como artes, ciência, sociedade, ser humano, moral, política, dentre outros. $\mathrm{Cu}$ riosamente, sob a alcunha de iluministas temos as mais diversas concepções de natureza, e consequentemente, as mais diversas teorias de qual seria a sociedade que seguiria os ditames da natureza. Podemos observar na obra, por exemplo, os defensores da educação pública e seus acusadores ou os defensores de uma moral conservadora e seus 
acusadores, mesmo que todos defendessem seus ideais para salvaguardar a natureza. Não existe uma unidade no interior do período sobre o que se considera natural, e consequentemente não há unanimidade sobre o que é o melhor modelo de sociedade.

Talvez se encontre uma univocidade se direcionarmos nosso olhar especificamente parao grupo de autores que recebe a alcunha de materialistas no período. Segundo Maria das Graças de Souza, podemosdefinir omaterialismoabrangentementecomo "uma redução do mundo propriamente humano ao campo da matéria, ou seja, ao campo da determinação natural [...] oprimado ou anterioridade da matéria sobre o espírito ou a consciência à matéria."(SOUZA. MARIA. 2009p. 283). Materialista é o que concebe a natureza e o mundo humano, - as construções históricas e culturais - a partir da primazia da matéria. Porém, se olharmos para as teorias de autores tidos como materialistas de acordo com a definição acima teremos uma pluralidade de teses distintas que partem aparentemente do mesmo princípio. Consciente de tal pluralidade, Ives Charles Zarka, separa os materialistas dentre os que acatariam o materialismo de necessidade, ou os que destacariam a aleatoriedade. No primeiro grupo, teríamos d'Holbach,querepresentaria o materialismo de necessidade, voltado para a determinação de tudo a partir da matéria e submetendo todo e qualquer acontecimento de cunho físico ou social às leis naturais. Representando o segundo grupo, Diderot ${ }^{3}$ daria um papel

\footnotetext{
${ }^{3}$ A aleatoriedade na obra de Diderot seria um"salto incompreensivel ou sequencia inesperada, [que] faz também a singularidade de um espírito, o estilo de um pensamento" (ZARKA, 2006, p. XV).Podemos relacionar essa compreensão da obra do autor com a designação de Ehrard sobre a hipótese da sensibilidade em Diderot como um salto no escuro (ver: SOUZA, M. Natureza e IlusCont.
} 
principal à contingência, à aleatoriedade de encontro entre moléculas. Além desta divisão, temos a que foi feita por Jean-Claude Bourdin (BOURDIN, 1996) entre os materialistas centrados na questão sobre o homem e sua orientação psicológica $^{4}$ (La Mettrie e Helvétius), e os materialistas da natureza de orientação cosmológica (Diderot e d'Holbach) ${ }^{5}$ .Tais divisões ilustram o fato de que nem mesmo dentro de um grupo específico de autores encontramos univocidade. Além disso, as divergências entre os autores eram constitutivas de suas obras e são um rico material para que possamos entender qual é o cerne de suas preocupações e objetivos. É necessário aproximarmos nosso olhar dos detalhes das teorias para compreender o que se entende por natureza e em que ponto estas noções se afastam, a ponto de resultarem em noções sobre a sociedade tão distintas entre si.

Para tanto, pretendemos analisar a querela entre Diderot e Helvétius para delimitar o ponto central a discordância entre os autores. Procuramos o ponto que separa os autores, como na divisão de Jean Claude Bourdin mencionada acima. Os temas aqui colocados concernem à concepção de ser humano e os prolongamentos que esta questão

tração.2003, p. 166). Adiante, veremos como a crítica de Maria das Graças a essa compreensão pode fomentar a investigação da querela entre Helvétius e Diderot.

${ }^{4}$ Segundo Bourdin, os primeiros "privilegiam a questão psicológica, da natureza da alma ou do espírito e suas relações com os corpos que, portanto, corresponde a uma ciência dos homens" (BOURDIN, 1996, p.24)

${ }^{5}$ As divisões aqui mencionadas não podem ser entendidas como complementares, já que em uma encontramos autores que recebem a mesma dominação enquanto na outra vemos os mesmos autores de lados opostos. É preciso que elas sejam especificadas para que seja nítido a que tema dentro do materialismo francês elas se referem. Sendo assim, elas não são mencionadas para estagnar a interpretação sobre o materialismo, mas como exemplo da diversidade e da singularidade de cada tese. 
pode ter, a saber: a importância da sensibilidade física para a formação das faculdades de raciocínio e memória; o desenvolvimento humano, entendido como o potencial de educação de cada ser humano; a formação da moralidade. A principal questão a ser respondida é: qual é o ponto de divergência que afasta o pensamento de autores considerados tão próximos?

Em Réfutatións d'Helvétius, texto que reúne a crítica diderotianasobre Del'Esprit (intitulada Refléxionssurle liure De l'Esprit) e De l'Homme (Réfutationsuivel'ouvrage d'Helvétius intitulé l'Homme), Diderot demarca sua distinção em relação a um autor menos renomado, mas que é frequentemente tido como muito próximo dele. Seu interesse na crítica da obra não pode ser considerado irrelevante, já que os temas ali abordados também foram tematizados em suas obras ${ }^{6}$. Mesmo assim, não se trata de classificarmos ou universalizarmos as colocações de Diderot, de modo a definir sua obra a partir dela. Ao contrário, trata-se de uma pesquisa sobre a discordância, que visa enfatizar as diferenças e contrariedades entre os trabalhos aqui analisados, com o objetivo de ressaltar a pluralidade de concepções sobre as temáticas mencionadas. Dessa forma, proporemos uma leitura dos possíveis desdobramentos que estariam em crisálida nas teorias sobre o desenvolvimento humano do século XVIII.

A crítica nos auxilia também no entendimento da re-

\footnotetext{
6 As obras de Diderot que mencionaremos no decorrer do texto não são ponto principal de pesquisa, mas mostram a aproximação do autor com os temas aqui colocados e podem mostrar diferentes posições. Elas foram selecionadas por terem sido escritas em períodos próximos ao das duas críticas ou da reunião das mesmas.
} 
cepção do pensamento de Helvétius entre seus pares. Suas obras ganharam notoriedade pela radicalidade como que o autor definia o ser humano: pensar e julgar se reduziriam a sentir: ${ }^{7}$

“... afirmo que a sensibilidade física e a memória ou, para falar com mais precisão, somente a sensibilidade produz todas as nossas ideias. Com efeito, a memória só pode ser um dos órgãos da sensibilidade física: o princípio que sente em nós deve ser necessariamente o princípio que se recorda, desde que se recordar, (...) é especificamente sentir." (Helvétius, Do Espírito. 1973. Coleção Os Pensadores. Abril Cultural, São Paulo. p. 183).

A partir do princípio de sensibilidade, Helvétius propõe o entendimento do desenvolvimento humano conectado com a recepções de sensações de prazer ou dor, que movem os seres e que possibilita o desenvolvimento da memória, dos julgamentos, da razão. A importância da investigação sobre o ser humano para o autor é a de conquistar um solo para a regulamentação educacional e moral para a melhora da sociedade. Como nos casos mencionados anteriormente, o que ocorre em leituras generalizantes sobre o século XVIII, ou sobre os materialistas, também poderia ocorrer no caso da relação entre Helvétius e Diderot: aparentemente, os temas são caros a ambos os autores e ambos possuem objetivos semelhantes, porém, as refutações reforçam o distanciamento entre eles.

\footnotetext{
${ }^{7}$ Como veremos, a frase não resume o princípio do autor sem dificuldades. Ela pretende descrever um processo de desenvolvimento que ocorreria a partir da sensibilidade e que, apesar de aparecer assim em De l'Esprit, é definido de forma diferente e mais detalhada em De l'Homme. Mesmo assim, o princípio é considerado falso por Diderot.
} 
Diderot faz uma crítica pontual a De l'Esprit (1754) que nos servirá de guia para a crítica mais detidasobreDe l'Homme (1771). Ele enumera os quatro paradoxos que embasam a obra de Helvétius:

"É fácil de ver que a base dessa obra [DoEspírito] apoia-se sobre quatro paradoxos...a sensibilidade é uma propriedade geral da matéria. Perceber, raciocinar, julgar,é sentir: primeiro paradoxo... não há nem justiça nem injustiça absoluta. $O$ interesse geral é a medida da estima dos talentos e essência da virtude: segundo paradoxo... é a educação e não a organização que faz a diferença dos homens, e os homens fora das mãos da natureza, todos igualmente próprios a tudo: terceiro paradoxo...o último fim das paixões são os bens físicos:quarto paradoxo..." (DIDEROT,Réfutations d'Helvétius.1877. p. 309. Tradução nossa) ${ }^{8}$

Os paradoxos que seriam os pilares da filosofia de Helvétius versam sobre: a sensibilidade física como propriedade da matéria, a inexistência de justiça, o poder da educação no desenvolvimento humano e a primazia do prazer.

\section{A PRIMAZIA DA SENSIBILIDADE.}

No primeiro paradoxo, sobre a primazia da sensibilidade física, Diderot questionaria como a sensibilidade física pode ser geradora de faculdades enquanto tais faculdades se reduzem a própria sensibilidade. Segundo Helvétius, a sen-

\footnotetext{
8 Os paradoxos enumerados por Diderot servirão de fio condutor para os temas principais das críticas. Contudo, não os abordaremos cronologicamente, na ordem em que aparecem na citação. Optamos por abordá-los pela ligação entre temas que eles suscitam tanto da crítica, quanto nas obras criticadas.
} 
sibilidade física seria uma característica intrínseca à matéria, presente em seres inertes ou ativos, em potência ou ato ${ }^{9}$. Ela é o elemento natural determinante no desenvolvimento humano, dada a ausência de qualquer faculdade anterior a ela, como em Condillac ${ }^{10}$. Mas, antes de considerá-la como determinante natural, é preciso ressaltar que a sensibilidade física é entendida como um canal de acesso,praticamente neutro, às sensações. Ou seja, dadas as diferentes condições sensoriais dos seres humanos, o resultado na capacidade de desenvolvimento não é uma desigualdade determinante ${ }^{11}$. Então se a sensibilidade propicia o desenvolvimento da memória e da razão, direciona a atenção dos seres humanos a partir do estímulo ao prazer e a repulsa ao desprazer, ela forma a concepção moral dos seres humanos a partir muito mais das sensaçõescom as quais elas têm contato do que uma condição prévia da sensibilidade física.

Ora, várias obras de Diderot investigam a sensibilidade, dentre elas, Carta sobre os cegos para o uso dos que veem, Diálogo entre Diderot e D'Alembert, Sonho de D'Alembert e Princípios sobre a matéria e o movimento. Em tais obras, Diderot estaria preocupado em compreender as relações entre a materiali-

\footnotetext{
${ }^{9}$ Para Helvétius, qualquer agrupamento de matéria possui sensibilidade física. Apenas parte deles é capaz de sentir pois em alguns ela estaria presente de forma inerte e só passará à atividade desde que faça parte de um novo agrupamento com determinada organização.

${ }^{10}$ Condillac descreve a gênese das faculdades oriundas da sensação a partir da alegoria da estátua de mármore, que ao ganhar sentidos gradualmente, desenvolve capacidades como memória e raciocínio. "O Traitédessensations mostra de forma inequívoca o primado da dimensão passional sobre a dimensão teórica (...) é na camada mais originária, a das afecções elementares, prazer/dor, das necessidades e dos desejos, que brota um sentido original, primordial, mas que será determinante"(MONZANI, 1996, p. 208).

${ }^{11}$ Nesse sentido, a organização corpórea, que teria destaque na diferenciação entre homens e animais anteriormente, perde importância quando se trata da distinção entre seres humanos. Dotados em sua maioria de uma organização corpórea semelhante, possuem a mesma capacidade de desenvolvimento.
} 
dade e o desenvolvimento humano, percurso no qual a sensibilidade física surge como ponto de investigação. Qual seria então o cerne de sua crítica ao que considera o primeiro paradoxo?

Diderot contraria Helvétius ao dizer que a sensibilidade física não seria a causa do desenvolvimento humano (de ideias, memória, raciocínio...), mas apenas uma condição para que ele ocorra, ao lado de características materiais como extensão e impenetrabilidade, por exemplo. Desse modo, não se podeconsiderá-la um princípio, mas apenas uma entre as demais características. Diderot utiliza a tese de que a sensibilidade estaria presente em todos os seres de forma ativa ou inerte, ao explicar a passagem da matéria ao pensamento $^{12}$. Mas ao ler De l'Homme, Diderot a critica por ser apenas uma hipótese ${ }^{13}$.

Haveria algo no lugar da sensibilidade física em primazia para Diderot? $\mathrm{O}$ autor, recusando a tese utilizada por ele anteriormente, diz que entende a relação entre a sensibilidade física e o pensamento, mas que o elo específico lhe escapa. As obras aqui mencionadas enfatizam que a causa seria anterior, reconhecida como a própria materialidade. É o que aparece quando Diderot explica como o mármore

\footnotetext{
${ }^{12}$ Em Principesphilosophiquessurlamatiére et lemouvement, Diderot enfatiza o movimento como atividade própria ou propriedade fundamental da matéria. A associação e dissociação entre moléculas propiciaria que a sensibilidade passasse da inatividade à atividade.

13 "Il faut en convenir, l'organisation ou la coordination de parties inertes ne mène point du tout à la sensibilité, et la sensibilité générale des molécules de la matière n'est qu'une supposition, qui tire toute sa force des difficultés dont elle débarrasse, ce qui ne suffit pas en bonne philosophie. Et puis revenons à notreauteur." (DIDEROT,Réfutations d'Helvétius.1877) Sobre isso, Maria das Graças de Souza, na conclusão de Natureza e Ilustração, coloca a hipótese como a que oferece maior clareza segundo Diderot. Nesse sentido, ela não seria negada pelo autor, mas também não teria o estatuto de verdade. Tal tese revelaria o naturalismo de Diderot, ao contrário da acusação de ocultismo feita por Jean Ehrard e Clement Rosset. Sendo assim, a passagem em que o autor utiliza a hipótese possui relevância na obra diderotiana e sua concepção de materialismo.
} 
pode passar de matéria inerte à ativa pela digestão: Se, ao alimentar-me, ingiro moléculas que pertenceram a algo de sensibilidade inativa, eles passam a ser parte de um ser ativo.Ora, se compreendo os seres como um agrupamento de moléculas e que segundo oPrincípios sobre a matéria e o movimento, essas moléculas possuem características diversas de ação e reação, dada a heterogeneidade da matéria, essas características irão operar diferentes possibilidades de desenvolvimento ${ }^{14}$.

Esta visão distinta sobre a relevância da sensibilidade física mostra que, ao contrário do que Helvétius coloca, Diderot não consideraria que o desenvolvimento humano é fruto das sensações de forma prioritária. As sensações fazem parte do processo, mas as diferenças entre os seres humanos podem ser encontradas em sua organização material, anterior a qualquer sensação:

"Página 12 - Os verdadeiros preceptores de nossa infância são os objetos que nos cercam.

- É verdade, mas como eles nos instruem?

- Pela sensação.

- É possível que a organização sendo diferente, a sensação seja a mesma? Tal é a diversidade, que se cada indivíduo pudesse criar uma língua análoga ao que se á, teríamos tantas línguas quanto indivíduos. Um homem não diria nem bom dia nem adeus como um outro.”(DIDEROT, Réfutations d'Helvétius, 1877. p. 311. Tradução nossa.)

\footnotetext{
${ }^{14}$ Sobre a passagem do estado inerte ao sensível através da digestão e a heterogeneidade da matéria, ver:DIDEROT. Da interpretação da natureza e outros textos. Trad. Magnólia Costa Santos. São Paulo: Iluminuras, 1989.
} 
Diderot, ao mencionar um trecho de De l'Homme simula um diálogo com o autor, onde questiona as possibilidades da educação. Enquanto Helvétius enfatiza que a sensibilidade abre caminho para a instrução que virá dos objetos que nos cercam, Diderot o questionaria sobre a organização, determinante capaz de diferenciar os seres. Disto, podemos depreender que o desenvolvimento humano não será compreendido da mesma forma pelos dois autores materialistas. $\mathrm{O}$ diferente estatuto dado à sensibilidade abre margem à duas concepções de ser humano distintas, o que nos leva ao terceiro paradoxo mencionado por Diderot, de que a educação diferencia os homens e é capaz de modificalos. O trecho acima mostra que a instrução dos homens, e consequentemente suas construções dependeriam de um elemento anterior.

\section{A EDUCAÇÃO.}

Helvétius concebe que a educação é o que forma o ser humano tal qual ele é, a partir das sensações, que seriam os primeiros professores. Toda interação entre o ser humano e os objetos que o cercam, através da sensação será um processo educacional, em que se aprende que sensações evitar e quais buscar, e assim que ações devem ser tomadas. O ser humano só se desenvolve através de um processo educacional, já que não possui faculdades previamente desenvolvidas. A concepção abrangente de educação pode ser entendida como instrução ou até mesmo o próprio desenvolvimento humano. Sendo assim, ser humano é ser educável.

Além disso, temos a educação pública como maior re- 
curso capaz de tornar uma sociedade justa e igualitária. Considerando uma educação desde a primeira infância que esteja consciente da importância do prazer e da moral, é possível articular os interesses particulares em prol do interesse comum. É preciso que ela seja a mesma educação para todos, para que possam ter interesses e oportunidades de desenvolvimento moral e intelectual próximos. Por isso, Helvétius enfatiza a importância de uma educação igualitária para uma sociedade sadia. Ela - aliada à legislação - é capaz de diminuir a desigualdade social e tornar os homens conscientes da relação entre eles, direcionando-os ao interesse comum, entendido como a reunião dos interesses mais básicos compartilhados por todos.

$O$ paradoxo denunciado por Diderot seria o de que a educação pode transformar o homem e melhorar a sociedade. Contudo, ela está subordinada ao acaso das experiências dos indivíduos, tornando-se incontrolável ${ }^{15}$. Sobre estas duas esferas de educação - uma considerada como o desenvolvimento humano e outra como educação institucional temos menções na obra de Diderot. Sobre a primeira, considerar a educação como fonte do desenvolvimento humano seria uma fraqueza do autor de Del'Homme:

Repete-se durante toda a vida as palavras dos primeiros anos: Cuida de ti mesmo... Se Helvétius tivesse bem pesado essas expressões de caráter, anteriores à toda educação, da idade do revestimento e dos ossículos, ele teria sentido que é a natureza que faz com que essas

\footnotetext{
15 "Se propor a mostrar a educação como única diferença dos espíritos, a única base do gênio, do talento e das virtudes e seguidamente abandonar ao acaso o sucesso da educação e da formação do caráter me parece que é reduzir tudo a nada e fazer ao mesmo tempo a sátira e a apologia dos instrutores."(DIDEROT,Réfutations d'Helvétius.1877. Tradução nossa)
} 
crianças sejam assim, e não a lição.(DIDEROT,Réfutations d'Helvétius.1877. p.280 Tradução nossa).

Assim, a primazia da educação ignoraria fatores inerentes ao indivíduo, que são próprios da natureza do indivíduo. Aqui, vemos uma diferente concepção de homem proposta: a concepção diderotiana expõe um diferente entendimento sobre a igualdade entre os indivíduos. Cada indivíduo possui naturalmente características que o diferenciam dos demais e que influenciarão sua possibilidade educacional. Ao contrário, Helvétius concebe a igualdade entre os seres humanos a partir da capacidade dada pela sensibilidade física, que tornaria todos aptos a serem educados.

Em sua refutação, o autor atenta ao perigo de considerar todos capazes dos mesmos feitos, já que uma educação igualitária tornaria todos medíocres. Ela não pode formar gênios, pois os únicos capazes de sê-lo possuem aptidões naturais para determinadas áreas. Para os que não possuem tais aptidões, a educação igualitária também seria maléfica por forçá-los a tentar superar-se de forma impossível, inclusive em conteúdos morais:

Não conheço nada mais desolador para as crianças que creiam que são próprias igualmente a tudo; nada mais capaz de cumprir as condições de uma sociedade de homens medíocres, de induzir a erro o gênio que faz bem uma coisa, nem mais perigosa pela obstinação que deve inspirar aos mestres que, depois de ter aplicado por um longo e infrutífero tempo uma classe de estudantes aos objetos pelos quais eles não tiveram nenhuma disposição natural, os rejeitarão no mundo onde não serão bons em nada. (DIDEROT,Réfutations d'Helvétius.1877. p.277 Tradução nossa). 
Se ambos os autores concordam na importância da educação através do acesso ao conhecimento para a melhora da sociedade,suas práticas divergem. Helvétius considera prejudicial à sociedade o desconhecimento da igual capacidade entre os homens, da gênese das faculdades a partir da sensibilidade. Principalmente, uma educação desigual afastaria ainda mais dos cidadãos, já tão afastados pelas circunstâncias, impossibilitando a apreensão do interesse comum. Sem uma educação igualitária, uma sociedade perece. Com ela, pode gerar grandes frutos, como indivíduos geniais e conscientes do interesse de sua sociedade. Enquanto isso, o trecho acima mostra que Diderot considera a proposta de Helvétius perniciosa. Primeiro, porque tal educação não consideraria as particularidades dos indivíduos e, segundo, porque tornaria os homens de gêniomedíocres, e os homens comuns frustrados.

Sobre a educação institucional, temos o Plano de Universidadede Diderot, em que a especificação da instrução por meio dos talentos individuais aparece. Em sua introdução, o autor lamenta a perda que o gênio pode sofrer mediante a educação pública, pois a educação pública deve ter como objetivo o alcance comum do espírito humano. Assim, os capazes teriam que aguentar o fardo de aguardar o ritmo dos incapazes. Por isso, a forma com que a educação pública pode auxiliar os gênios é não os sufocando. A estrutura ali proposta é dividida em campos que serão direcionados a partir das aptidões individuais, como medicina, direito ou artes, e um núcleo comum, voltado à moral ${ }^{16}$.

\footnotetext{
${ }^{16}$ Sobre esse núcleo comum, podemos atentar outro motivo para a rejeição de Diderot à proposta Cont.
} 
Antes de considerar a questão da moral, deve-se entender a gênese das paixões pelo princípio de prazer segundo Helvétius, bem como a crítica feita por Diderot.

\section{AS PAIXÕES E OS PRAZERES.}

Da primazia da sensibilidade, decorre também a primazia da busca pelos prazeres e o afastamento da dor. Dentro da primeira concepção de educação, nossos sentidos são educados pelas sensações a sempre buscar os prazeres e evitar as dores, o que contribui para a manutenção da sobrevivência e a vivacidade dos indivíduos. Por isso, eles possuem um grande papel para Helvétius.

Como mostra Desejo e Prazer na idade Moderna, de Luiz Roberto Monzani (1995), os prazeres são anteriores a qualquer desejo u paixão, já que não haveria nada de inato além da capacidade de sentir. Por isso, os prazeres são a primeira forma e origem das paixões, entendidas como o desejo prolongado no decorrer da vida por determinada forma de prazer.

Para Diderot, o paradoxo estaria na redução das paixões aos prazeres, de que toda paixão existe em vistas de um prazer físico:

Quantos homens que, depois de ter esgotado em sua juventude toda a felicidade física que se pode esperar das paixões, tornam-se avaros, os outros ambiciosos, os outros amantes da glória! Devemos dizer que eles têm em vista, em sua nova paixão, aqueles bens dos quais estão desgostosos? (DIDEROT, Réfutations d'Helvétius, 1877 p.

de Helvétius: a forma como a moral seria ensinada, o que nos leva à preocupação com a formulação de uma moral e o conceito de justiça. 
265. Tradução nossa).

Como é possível que os indivíduos busquem prazeres dos quais já se serviram a ponto de não mais o quererem? Seria um erro uma aproximação tão grande entre os prazeres e paixões. Então a fonte primária das paixões deve ser outra, ou ao menos deve considerar outros elementos. Contudo, as paixões constituem do caráter moral dos indivíduos. Assim, é preciso pensar em como Diderot concebe a moralidade, o que nos leva ao paradoxo sobre a justiça.

\section{A MORAL.}

Sobre o quarto paradoxo aqui tematizado, temos a inexistência ou falta de fixidez do que se considera justiça. Helvétius aponta para a ausência de uma noção universal de virtude como normas de conduta específicas, e passa a tratar da virtude de probidade. Novamente, essa ausência se dá na circunstancialidade do desenvolvimento humano, o que faz com que cada ação dependa de seu contexto. Para Diderot, outro pensamento perigoso do autor criticado. Helvétius teria ignorado a existência de uma justiça universalque acarretaria na permissividade extrema e a ausência de parâmetro de ação, o que levaria os homens ao vício e uma sociedade à ruína. É o que Jean Ehrard aponta como real motivo da recusa da proposta educacional de Helvétius. Uma educação moral igualitária com ausência de uma noção de justiça seria altamente reprovável.

$\bigcirc$ autor da crítica não menciona nas Refutações nenhuma justiça universal que ultrapasse o interesse. Mas ele 
aponta para a ideia de que existiriam parâmetros morais calcados na natureza em obras como Jacques o Fatalista, O filho Natural, e Suplemento à Viagem de Bougainville. No caso do Suplemento, vemos a repercussão das leis da natureza, como a fertilidade, ampararem as leis de um povo distante dos europeus - que possui certa superioridade moral pela coerência de seu sistema frente à impostura da moral francesa.

O diálogo entre $\mathrm{A}$ e $\mathrm{B}$ mostra como ocorre a recepção dos escritos de Bougainvillle sobre a viagem ao Taiti, tematizando os costumes taitianos e sua relação com a sociedade francesa e com a natureza. Enquanto os costumes franceses são mencionados como imposturas da religião, sem justificativas além do poderio religioso, rigor e pudor, os costumes taitianos - mesmo que não sejam tomados como ideais - mostram a conformidade com a natureza e o recanto da liberdade e da felicidade. Os bons costumes são julgados pela conformidade com a natureza e a fertilidade. Por exemplo, em relação ao casamento, os costumes do estrangeiro são considerados:

Não vês que confundiram, em teu país, a coisa que não tem sensibilidade, nem pensamento, nem desejo, nem vontade; que se larga, que se toma, que se guarda, que se troca sem que ela sofra e sem que ela se queixe, com a coisa que não se troca, que não se adquire,de modo algum; que tem liberdade, vontade, desejo; que pode dar-se ou recusar-se para sempre; que se queixa e que sofre; e que não poderia tornar-se uma letra de câmbio, sem que seja esquecido o seu caráter e que se faça violência à natureza? (DIDEROT. Suplemento à viagem de Bougainville.1973.p.137).

Porém, depois da leitura dos depoimentos de Oru e do 
Capelão, A e B questionam a moralidade: quais seriam os critérios para julgar a boa moral? Entre a lei civil e a religiosa ambas devem estar submetidas à lei natural: alei religiosa se torna supérflua e a lei civil deve ser a enunciação da lei da natureza. Quando A menciona que a lei da natureza estaria gravada em nossos corações, o que mostraria alguma forma de inatismo nas leis, $\mathrm{B}$ o corrige:

\footnotetext{
"Não trazemos ao nascer senão uma similitude de organização com outros seres, as mesmas necessidades, a atração para os mesmos prazeres e uma aversão comum às mesmas penas: eis o que constitui o homem como ele é, e deve fundamentar a moral que lhe convém.” (DIDEROT. Suplemento à viagem de Bougainville1973.p.137)
}

A partir desse breve percurso, destacamos algumas considerações que esclarecem a ligação entre natureza, desenvolvimento humano e moral para os autores. Nossa tese é a de que a oposição frente ao primeiro paradoxo, a saber, a oposição entre a primazia da sensibilidade física e ascaracterísticas inerentes à matéria, dá vasão as demais oposições. Nesse sentido, Diderot conceberia a ligação entre natureza e moral como uma determinação com maior fixidez, que levará a consideração das leis naturais mais presentes no desenvolvimento moral individual e social, limitando assim suas possibilidades de melhora ou de transformação. Em sentido contrário, a ligação que Helvétius concebe entre natureza e moral tem outra perspectiva. Segundo seu entendimento da natureza humana, ao invés da sensibilidade física determinar limites precisos ao desenvolvimento humano, ela lança o indivíduo tendo como única diretriz sentir, ao conjunto de possibilidades tão grande quanto o 
conjunto de possíveis sensações, deixando em um aberto permanente o desenvolvimento, que só há de cessar com a destruição do corpo material.

Até aqui, utilizando as divisões mencionadas no início do texto, podemos compreender que na primeira divisão, no que concerne ao papel da aleatoriedade na obra, Helvétius e Diderot estariam no mesmo grupo, por considerarem a aleatoriedade constitutiva da formação dos seres e também do desenvolvimento de suas faculdades após sua formação material. Mas também podemos reafirmar a oposição feita por Jean- Claude Bourdin, em que Diderot teria uma concepção cosmológica da dinâmica da natureza que aponta para o que se é, enquanto Helvétius enfatiza o cenário de convenções e uma formação psicológica, para o que se pode tornar. Diderot, nos temas aqui mencionados parece atender a uma ordem cosmológica a qual os indivíduos, seu desenvolvimento e a moralidade devem atender.

Porém, resta ainda a consideração do julgamento de valor de um sistema tão aberto quanto o de Helvétius, uma base universal de moral que se encontraria entre a destinação natural ao prazer e a construção humana dos costumes. Tal crítica não pode ser resumida às propriedades materiais, pois toca no cerne do desenvolvimento da sociedade. Além disso, o autor acredita que a educação pode aperfeiçoar a sociedade. Assim, é preciso investigar ainda o entendimento da moral para Diderot e qual o papel do meio na formação dos indivíduos. Em alguns momentos ela aparece colada à natureza, enquanto em outros, aparece como outra hipótese: 
“(...) a estabelecer seu paradoxo favorito: 'Que a educação sozinha faz toda a diferença entre os indivíduos semelhantemente bem organizados...' condição na qual ele não faz entrar nem a força, nem a fraqueza, nem a saúde, nem a doença, nenhuma das qualidades físicas ou morais que diversificam os temperamentos e os caráteres." (Diderot,Réfutations d'Helvétius.1877. p.265. Tradução nossa.)

A educação deve observar a moralidade dos indivíduos ao lado de suas características físicas. Parece haver uma complementaridade entre elas e não uma simples continuidade. Em Sobrinho de Rameau, a tendência que determina os seres aparece na figura do sobrinho e sua genialidade como artista, mas também em sua incapacidade para a virtude. Para tentar justificar essa tendência, o sobrinho lança mão de duas hipóteses: pode ser por causa de uma partícula paternal passada hereditariamente que o formou dessa maneira, ou pode ser que ele tenha vivido sempre rodeado de pessoas de má índole e bons hábitos artísticos ${ }^{17}$.

Sendo assim, é preciso avaliar qual é o grau de permanência das características naturais dos indivíduos e como elas reagem com a construção cultural e a circunstancialidade das experiências para melhor compreender a crítica e também os projetos de sociedade ali em atrito.

\footnotetext{
17 "EU - Como é possível que com um tato tão fino, uma sensibilidade tão aguçada para as belezas da arte musical sejais tão cego para as belas coisas da moral, tão insensível aos encantos da virtude?

ELE - Aparentemente porque parece haver para elas um sentido que não tenho, uma fibra que não me foi dada ou que é tão frouxa que não adianta beliscá-la porque não vibra. Ou talvez porque tenha vivido sempre entre bons músicos e má gente, e, assim, meu ouvido tornou-se muito fino e meu coração, surdo. E depois parece que a raça também conta. $\mathrm{O}$ mesmo sangue corre nas veias de meu pai e de meu tio. A molécula paterna deve ter sido dura e obtusa e esta maldita primeira molécula deve ter Sido assimilada por todo o resto." (Diderot. Diálogo entre Diderot e D’Alembert, 1973, p 181).
} 
Abstract: There is an acknowledged proximity amongst French materialists in the 18th century that has been shown both in investigations about nature, public morality, and organization. However, the divergences amongst them can trigger a very different understanding of how a society is considered. That is why it is necessary to analyze these divergences in their details to determine their critical point. This article is dedicated to the investigation of the criticisms made by Diderot to Helvétius, gathered in Réfutationsd'Helvétius (DIDEROT, 1783). Therefore, it focuses on the distinct conception of the nature of human sensitivity and its importance for human development in what concerns to education and morals.

Key-Words: Helvétius, Diderot, sensibility, education.

\section{REFERÊNCIAS}

BOURDIN, JEAN-CLAUDE. Les Matérialistes au XVIIIe siècle.Paris. Payot. 1996.

DIDEROT,D. Oeuvres complètes de Diderot. Org. J. Assézat [et Maurice Tourneux].Ed. J. Claye. Paris. 18751877.

. O sobrinho de Rameau, Diálogo entre D ${ }^{e}$ Alembert e Diderot, O sonho de D"Alembert, Continuação do Diálogo, Suplemento à Viagem de Bougainville, Paradoxo sobre o comediante, Dos autores e dos críticos. In: Diderot. Trad. Marilena Chaui. (Col. "Os Pensadores").São Paulo: Abril, 1973.

Plano de Universidade. In: Obras I- Filosofia e Política. Tradução: Guinsburg. Perspectiva. São Paulo. 2000.

GUINSBURG, J. Diderot: o espírito das Luzes. São Paulo: Ateliê, 2002. HELVÉTIUS, C-A. 1989. De l'Homme. 
Paris: Fayard.

.1973 Do Espírito.Coleção Os Pensadores. São Paulo: Abril Cultural.

MONZANI, L.R.1995. Desejo e Prazer na Idade Moderna.Campinas, SP: Editora da Unicamp.

ROSTAND, J. 1951. La conception de l'homme selon Helvétius et selon Diderot. In: Revue d'histoire dessciences et de leurs applications.Paris, Presses Universitaires de France.Tome 4 n ${ }^{\circ}$-4. pp. 213-222.

SOUZA, M. Natureza e ilustração sobre o materialismo de Diderot. São Paulo: Ed. Unesp, 2003.

Matéria e história nas luzes francesas, in: Necessidade e contingência na modernidade. Org. Luís César Guimarães Oliva.p. São Paulo. Barcarolla, 2009, p.283296.

ZARKA. YVES CHARLES. Matérialistes français du XVIIIE siècle: La Mettrie, Helvétius, d'Holbach.Presses Universitaires de France. Paris, 2006. 